\title{
ÉTICA E DIREITOS HUMANOS: PROPOSTAS PARA INIBIR PRÁTICAS VIOLADORAS NA SOCIOEDUCAÇÃO
}

ETHICS AND HUMAN RIGHTS: PROPOSALS TO INHIBIT VIOLATING PRACTICES IN SOCIOEDUCATION

ETICA Y DERECHOS HUMANOS: PROPUESTAS PARA INHIBIR PRÁCTICAS VIOLADORAS EM LA SOCIOEDUCACIÓN

Graciela Alves ${ }^{1}$, Sidelmar Alves da Silva Kunz², Silvia da Silva Correa ${ }^{3}$

\section{RESUMO}

Esta pesquisa avaliou se a ética aliada aos direitos humanos pode colaborar para a redução de práticas violadoras de direitos na socioeducação, sobretudo em relação às atividades realizadas pelos profissionais com foco no público atendido. Trata-se de uma abordagem qualitativa, em que as informações foram construídas por intermédio de questionário semiestruturado aplicado a vinte profissionais de quatro Centros de Referência de Assistência Social (CREAS) e duas ONGs no Estado de São Paulo, que oferecem Serviço de Proteção Social aos adolescentes em Cumprimento de Medida Socioeducativa. Os resultados apontam que a ética é fator imprescindível para a promoção de direitos, especialmente na transformação e combate as violações e superação da violência. Em face disso, a associação entre ética e direitos humanos se constitui como um expressivo desafio para os profissionais da socioeducação.

PALAVRAS-CHAVE: Ética. Direitos Humanos. Socioeducação.

\section{ABSTRACT:}

This research evaluated whether the ethics associated with human rights can contribute to the reduction of practices that violate rights in socio-education, especially in relation to the activities carried out by professionals with a focus on the public served. It is a qualitative approach, in which the information was constructed through a semi-structured questionnaire applied to twenty professionals from four Reference Centers for Social Assistance (CREAS) and two ONGs in the State of São Paulo, which provide Social Protection Service to Adolescents in Compliance with Socioeducational Measures. The results indicate that ethics is an essential factor for the promotion of rights, especially in the transformation and combat of violations and overcoming violence. In this regard, the association between ethics and human rights is an important challenge for the professionals of the socio-education.

KEYWORDS: Ethics. Human rights. Socioeducation.

1 Especialista em Políticas Públicas e Socioeducação pela Escola Nacional de Socioeducação/Universidade de Brasília (ENS/UnB) e Especialista em Psicologia do Trânsito pela Universidade São Francisco (USF). Atua como psicóloga no Centro de Referência Especializado em Assistência Social (CREAS) em Paulínia/SP. Correio eletrônico: gracielaalves86@gmail.com

2 Doutorando em Educação (FE/UnB). Pesquisador do Inep. Orientador de monografias de especialização na UnB e na UFG, nas áreas de direitos humanos, educação e patrimônio cultural e artístico. Correio eletrônico: sidel.gea@gmail.com

3 Possui Bacharelado e Licenciatura em Geografia pela Universidade Federal do Pará (UFPA) mestrado em Geografia pela Universidade Federal de Rondônia (UNIR). Atualmente é professora de Geografia e Estudos Amazônicos na Prefeitura Municipal de Oriximiná-PA. Correio eletrônico: silvia.silvacorrea@gmail.com 


\section{RESUMEN:}

Esta investigación evaluó si la ética aliada a los derechos humanos puede colaborar para la reducción de prácticas violadoras de derechos em la socioeducación, sobre todo em relación a las actividades realizadas por los profesionales con foco en el público atendido. Se trata de un enfoque cualitativo, en el que las informaciones fueron construidas a través de um cuestionario semiestructurado aplicado em veinte profesionales de cuatro Centros de Referencia de Asistencia Social (CREAS) y dos ONGs en el Estado de São Paulo, que ofrecen Servicio de Protección Social a Adolescentes en Cumplimiento de Medida Socioeducativa. Los resultados apuntan que la ética es un factor imprescindible para la promoción de derechos, especialmente en la transformación y combate de las violaciones y superación de la violencia. En vista de ello, la asociación entre ética y derechos humanos se constituye como un expressivo desafío para los profesionales de la socioeducación.

PALABRAS CLAVE: Ética. Derechos humanos. Socioeducation.

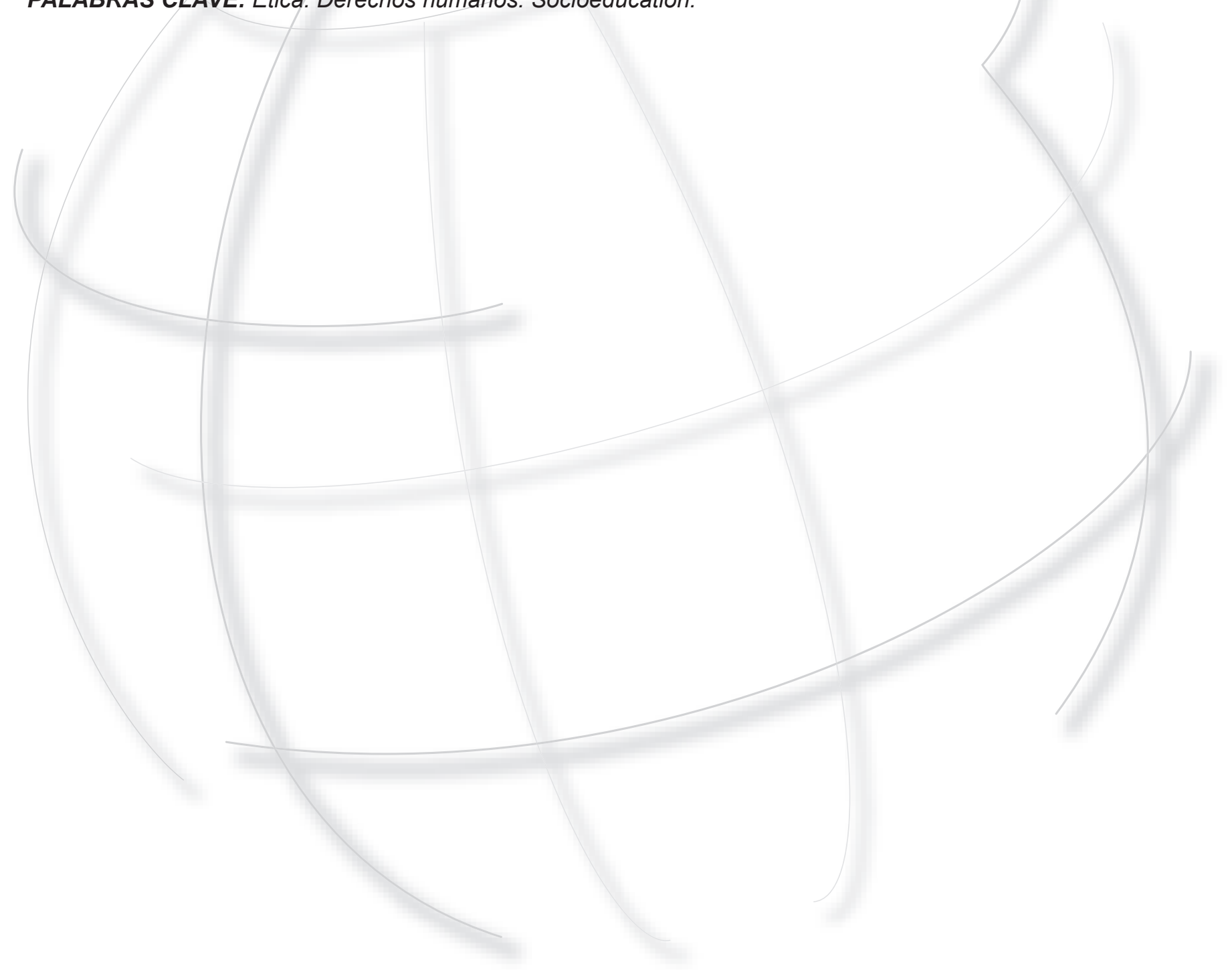




\section{Introdução}

As práticas violadoras de direitos desafiam a sociedade contemporânea, de modo especial, a participação das instituições e da socioeducação no processo de superação e inibição das afrontas aos direitos humanos fundamentais. Os operadores do sistema socioeducativo, são elementos essenciais nesse processo e em razão disso, devem mediar suas práticas e obrigações na ética, na proteção e valorização integral do indivíduo combatendo todo ato contrário. Nesse ponto de partida, objetivamos neste trabalho analisar a relação entre a ética e os direitos humanos, na busca pela redução de práticas violadoras de direitos nos atendimentos ofertados pelas instituições socioeducativas.

A socioeducação surgiu na implementação de medidas normatizadas pelo Estatuto da Criança e do Adolescente (ECA), com o objetivo de promover a proteção e reinserção infanto-juvenil, de direitos violados, bem como reintegrar após medidas socioeducativas ao convívio social, adolescentes em situação de conflito com a lei. A atuação do socioeducador não pode ser contrária a de um defensor dos direitos humanos que visa proteger ao invés de punir, garantir ao invés de violar direitos. Pontua-se que garantir direitos é responsabilidade de todos os envolvidos no processo. Em face disso, torna-se fundamental conhecer quem são os profissionais operadores de direitos humanos que atuam com adolescentes em conflito com a lei e que estão inseridos em um contexto de vulnerabilidades sociais.

As normas e os princípios éticos são elementos nevrálgicos para a construção de conhecimentos, a internalização de valores e a condução de práticas que qualifiquem a atuação dos profissionais envolvidos. $\mathrm{O}$ respeito e a dignidade são princípios caros que devem pautar as ações de todos os mediadores da socioeducação, para que ocorra a promoção dos direitos humanos. Assevera-se, com base em Schmidt (2017), que a reflexão acerca dos direitos humanos tem a dimensão sócio-histórica como pressuposto na luta pela superação da opressão, da exploração e das desigualdades.

Acredita-se que a ética aliada aos direitos humanos pode fazer frente às violações de direitos. Para Freire (1996) a ética é universal do ser humano e inseparável da prática socioeducativa. Neste recorte, postula-se a ética como sendo aquela "[...] afrontada na manifestação discriminatória de raça, de gênero, de classe. É por esta ética inseparável da prática educativa, não importa se trabalhamos com crianças, jovens ou com adultos, que devemos lutar" (FREIRE, 1996, p. 9-10).

Assim sendo, é necessário fazer da luta pela ética uma prática constante na relação com os educandos. Nessa esteira de ideias, este artigo traz uma reflexão acerca desses dilemas que envolvem a afronta aos direitos humanos vivenciados pelos profissionais, em face dos princípios e fundamentos éticos atinentes à realização das atividades dos socioeducadores dando conta da necessidade de preservar direitos que anteriormente não eram considerados.

\section{Princípios éticos e direitos humanos: o que os da- dos revelam na socioeducação do Estado de São Paulo?}

Dado o problema de pesquisa que é saber se a ética relacionada aos direitos humanos pode colaborar para a redução de práticas violadoras de direitos, essa pesquisa de campo teve como aporte metodológico a abordagem qualitativa, onde os dados coletados foram por intermédio de um questionário semiestruturado, contendo onze questões abertas e fechadas. O questionário foi aplicado com profissionais da socioeducação, no mês de junho de 2018. Este instrumento passou por um processo de pré-testagem que consistiu na submissão para análise de dois profissionais socioeducadores e um pesquisador sênior, cujas sugestões de adequação subsidiaram o refinamento do instrumento.

A coleta de dados foi realizada em 04 Centros de Referência Especializados de Assistência Social (CREAS) e 02 ONGs (Organizações Não Governamentais) vinculadas aos CREAS, no interior do estado de São Paulo em que figura o Serviço de Proteção Social a Adolescentes em Cumprimento de Medida Socioeducativa. Participaram da pesquisa 20 profissionais (de nível superior) atuantes nessas instituições, sendo nove assistentes sociais, cinco psicólogos/as, quatro terapeutas ocupacionais, um/a pedagogo/a e um/a sociólogo/o, destes 14 trabalham em regime celetistas e 06 são profissionais concursados.

$\mathrm{O}$ entendimento de que os princípios do Estatuto da Criança e do Adolescente (ECA), bem como os presentes no Sistema Nacional de Atendimento Socioeducativo (SINASE), devem estar alicerçados nos fundamentos dos direitos humanos, os quais concebem valores éticos (SCHMIDT, 2017). Complementarmente 
a essa ideia, Freire (1996), aborda o conceito de que a prática socioeducativa comporta uma natureza ética, por isso, se assume a necessidade de encampar a perspectiva ética, pois todo ser humano sempre estará exposto à sua transgressão.

Compreender como os socioeducadores fundamentam suas práticas cotidianas é fundamental para avaliar se os espaços socioeducativos realmente garantem a não violência e a promoção dos direitos humanos. Nesta perspectiva, se questionou: Ter um perfil profissional deve ser um elemento indispensável para a contratação destes? Na Figura 1, em uma escala de 1 a 5, em que o " 1 " expressa o discordo completo e o " 5 " evidencia o concordo pleno, obteve-se o seguinte resultado:

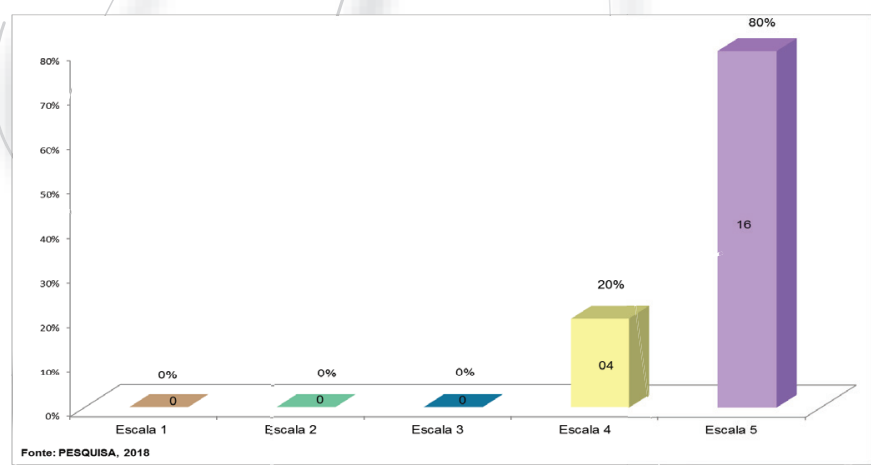

Figura 1. Perfil profissional

Fonte: Elaboração dos autores.

A maioria dos socioeducadores 16 (80\%) concordam plenamente que o perfil profissional é um requisito indispensável na contratação do profissional, o que corrobora com a recomendação do SINASE (2006), que afirma que para o acompanhamento dos adolescentes em cumprimento de medidas socioeducativas em meio aberto, o perfil dos técnicos exige que estes tenham experiência e conhecimento técnico de trabalho no sistema e atendimento socioeducativo, além de experiência de trabalho em serviços, programas e projetos que atendam os adolescentes e que integrem as categorias profissionais.

Contraditoriamente, na prática a questão do perfil profissional não é visto como uma prioridade para contratação, o que foi confirmado na pesquisa de Moraes e Malfitano (2014), onde estas autoras identificaram que a inserção dos socioeducadores no sistema, se dá por aprovação em concurso público ou seleção por especialidade. O perfil profissional representa apenas $12 \%$ dos entrevistados nas pesquisas destas, concluindo que o socioeducador precisa possuir um "perfil" para atuar na mediação de conflitos e nas medidas socioeducativas, os quais interesse, aproximação e empatia com a temática e o público atendido, conforme também identificamos no recorte espacial em estudo.

Em seguida, baseado nas características do que são direitos humanos contidas na Declaração Universal dos Direitos Humanos (2009) perguntou-se aos participantes da pesquisa, dentre as 4 alternativas (apresentadas abaixo), qual não tinha relação com direitos humanos e em função disso deveria ser excluída/desconsiderada. As alternativas na íntegra estão registradas na sequência, bem como a figura que expressa a escolha dos participantes no que se refere a qual alternativa é contrária aos direitos humanos.

Alternativa 1 - Todos os seres humanos nascem livres e iguais em dignidade e direitos. São dotados de razão e consciência e devem agir em relação uns aos outros com espírito de fraternidade.

Alternativa 2 - Todo ser humano tem capacidade para gozar os direitos e as liberdades estabelecidos nesta Declaração, sem distinção de qualquer espécie, seja de raça, cor, sexo, idioma, religião, opinião política ou de outra natureza, origem nacional ou social, riqueza, nascimento, ou qualquer outra condição.

Alternativa 3 - Todo ser humano tem direito à vida, à liberdade e à segurança pessoal. Ninguém será submetido à tortura nem a tratamento ou castigo cruel, desumano ou degradante.

Alternativa 4 - Os Direitos humanos constituídos na Declaração Universal dos Direitos Humanos, não são para todos, portanto, não precisam ser respeitados.

Sobre esse aspecto, os dados da Figura 2 apontam que:

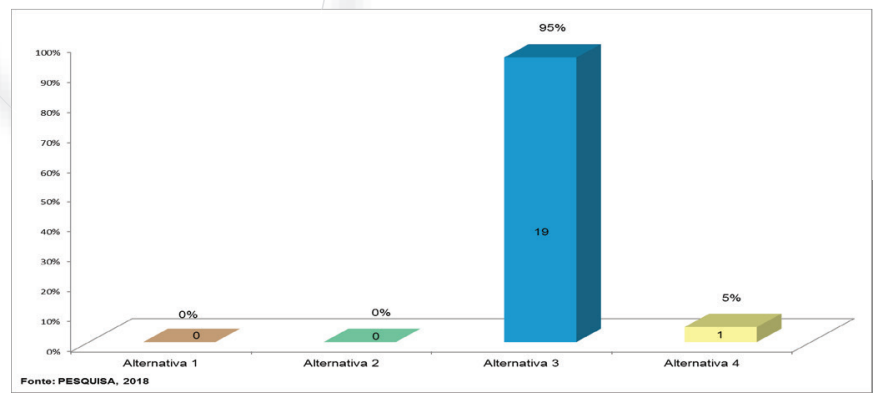

Figura 2. Qual alternativa é contrária aos direitos humanos? Fonte: Elaboração dos autores. 
Considerando que apenas uma opção (a Alternativa 4: Os Direitos humanos constituídos na Declaração Universal dos Direitos Humanos, não são para todos, portanto, não precisam ser respeitados) não tinha compatibilidade ou contraria a garantia dos direitos humanos, notamos que dos vinte entrevistados quase todos (dezenove ou 95\%) se equivocaram, haja vista que optaram por uma alternativa (a alternativa 3) que é compatível com a defesa dos direitos humanos. A partir desses dados, parece que de alguma maneira os socioeducadores estão sendo levados a compreender que os direitos humanos constituídos na Declaração Universal dos Direitos Humanos não são para todos, portanto, não precisam ser respeitados.

Fabriz (2003, p. 239-240), afirma que a dignidade da pessoa humana deve permear direitos fundamentais, ao passo que:

Os direitos humanos, em princípio, constituem a proteção mínima que permite ao indivíduo viver uma vida digna, defendendo-a das usurpações do arbítrio estatal (ou outro); configurando-lhe um espaço sagrado, intransponível, traçando à sua volta uma esfera privada inviolável. Revelam-se como um conjunto de normas que visam defender a pessoa humana contra os excessos do poder ou daqueles que exercitam o poder, visto que também são oponíveis contra atos de outros indivíduos (FABRIZ, 2003, p. 239-240).

Conhecer sobre quais são os direitos humanos é fundamental para todos os cidadãos, principalmente para aqueles que são operadores de direitos e cuja missão é buscar impedir que esses direitos sejam violados. Portanto, os dados revelam que a maioria dos socioeducadores tem conhecimento sobre o que são direitos humanos, todavia, acredita-se que apenas ter conhecimento sobre direitos não é o suficiente, é necessário internalizá-lo e praticá-lo.

Considerando a ética como equilíbrio da conduta humana atrelada aos valores e princípios que regem o bom funcionamento social, perguntou-se aos profissionais se acreditam que a ética pode ser uma aliada no combate às violações de direitos, e do total da amostra, ou seja, dos 20 socioeducadores, $18(90 \%)$ acreditam plenamente que a ética pode ser uma aliada no combate às violações de direitos, conforme explica Schmidt (2017, p. 24):
É optarmos pela concepção de adolescente como sujeitos de direitos, ou seja, estarmos orientados por uma perspectiva ética na defesa dos direitos humanos destes adolescentes é estarmos na busca incessante de decifrarmos a vida destes jovens, e juntamente com estes e suas famílias e com articulação com o sistema de garantia de díreitos, construir alternativas que possibilitem outras possibilidades de vida. A ética então possui um papel central nesta direção, ela nos possibilita um olhar para este adolescente para além de um fato jurídico, um olhar da totalídade do fenômeno, bem como nos sintoniza com nossa prioridade (os adolescentes e seus direitos) e nos impede de produzir práticas a partir de olhares preconceituosos e moralistas. (SCHMIDT, 2017, p. 20).

Pelo exposto, a ética é uma importante aliada no combate às violações de direitos, como também se apresenta como um desafio e uma orientação constante para os profissionais, pois possibilita-os olharem para o público atendido, como pessoas que vivem, sonham, aprendem, que possuem necessidades, vontades e a sua subjetividade e não apenas para um adolescente que tem uma determinação judicial a cumprir como forma de punição.

A medida socioeducativa responsabiliza o adolescente pelos seus atos, mas se a ética não for uma aliada no combate às violações de direitos, corre-se o risco de ser atribuído um caráter punitivo no cumprimento das medidas socioeducativas, ao invés de se considerar o duplo caráter das medidas: o sancionatório e o pedagógico. Portanto, a ética é peça indispensável para fazer frente às violações de direitos.

Outra situação abordada foi saber se os socioeducadores concordam ou não que os princípios em direitos humanos do SINASE e do ECA possuem valores éticos. Dos 20 entrevistados, mais de $60 \%$ concordam que o SINASE e o ECA possuem valores éticos. Pontua-se que o SINASE (2006), define que todo o trabalho desenvolvido deve ter seu sustentáculo em bases éticas e pedagógicas, corroborando com o que dispõe o ECA, que a humanização das relações e a proteção da criança e adolescentes devem ser pautados em valores e princípios éticos.

Destarte, acredita-se que esses princípios éticos devem nortear a prática desses profissionais, uma vez 
que não se trata apenas de regras a serem cumpridas, mas sim, de possibilidades a partir de um olhar mais humanizado. Esses valores éticos intrínsecos permitem que crianças e adolescentes possam ser vistos como pessoas de direitos, em desenvolvimento e que devem ser respeitadas e acima de tudo, permitem um olhar para essas leis no coletivo, quando trazem a moral em seu alicerce e tornam possível observar que todos são responsabilizados enquanto sociedade por garantir esses direitos.

Acerca do conhecimento e fundamentação do ECA e do SINASE, que deve nortear e conduzir as práticas dos socioeducadores, investigou-se se estes possuem conhecimento aprofundado dessas leis, os resultados apontam que dos 20 sujeitos da amostra, a maioria acredita que mais de $60 \%$ dos entrevistados conhecem as leis do SINASE e do ECA, enquanto que $40 \%$ afirmam que conhecem superficialmente essas leis. Isto reflete no comportamento ético que é exigido na prática dos profissionais, já que não se pode garantir direitos desconhecendo a finalidade e a legislação que os direciona, buscando a superação da violência e a garantia efetiva de direitos.

Observa-se que ter conhecimento teórico e específico em relação à área de atuação é fundamental conforme afirma o SINASE (2006), "é imprescindível a composição de um corpo técnico que tenha conhecimento específico na área de atuação profissional e, sobretudo, conhecimento teórico-prático em relação à especificidade do trabalho a ser desenvolvido". Acredita-se, que os socioeducadores além de precisarem efetivar em suas atividades as normativas, do SINASE e do ECA, devam conduzir e aprofundar suas práticas em outras duas importantes ferramentas de promoção de direitos, a Constituição Federal e a Declaração Universal dos Direitos Humanos.

Acredita-se que em outro momento, possa ser feito um aprofundamento a esse respeito, uma vez que não é possível dizer a priori que tipo de conhecimento eles têm, ou qual a intensidade que conhecem. Entretanto, ao conhecer as leis que norteiam uma prática, esta por sua vez, deve tornar-se um instrumento mediador de sua atuação, e contribuir para a transformação de uma realidade. Isso porque, a teoria, como fio condutor, pode transformar a prática e assim, contribuir para uma melhor efetivação das políticas públicas.
Considerando os direitos dos adolescentes em cumprimento de medidas socioeducativas e a ética, questionou-se se ao longo de sua atuação profissional estes já presenciaram socioeducadores produzindo práticas violadoras de direitos. A Figura 3 retrata o resultado obtido.

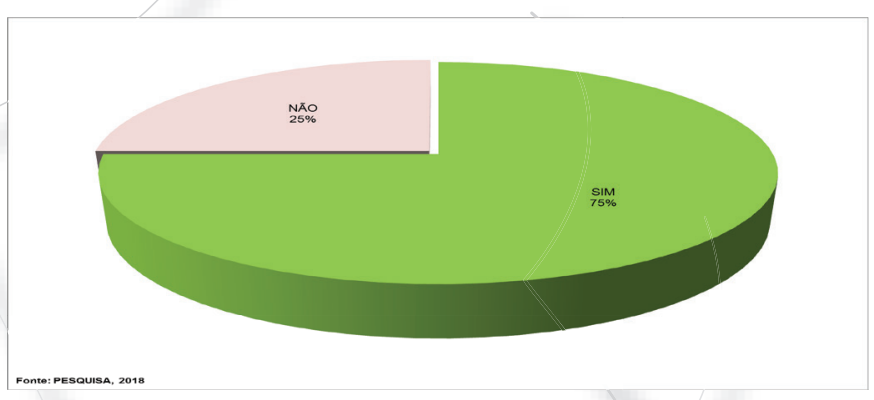

Figura 3. Profissionais que presenciaram socioeducadores produzindo práticas violadoras de direitos Fonte: Elaboração dos autores.

Dos 20 sujeitos, $75 \%$ já presenciaram práticas violadoras de direitos, as respostas profissionais indicam variadas situações de violações de direitos, conforme relatos presentes no Quadro 1.

Quadro 1. Relatos de ter assistido violações de direitos por parte de socioeducadores

Uma vez na Fundação CASA uma técnica, ao ver que o adolescente estava com marcas de agressão no seu corpo, perguntou o que havia acontecido. O adolescente então descreveu que havia sofrido violência policial no momento da sua apreensão. A técnica então virou para mim e falou que a polícia era assim mesmo e que ela não precisava fazer uma denúncia (SOCIOEDUCADOR 1).

Adolescente sendo exposto através de adjetivos pejorativos (SOCIOEDUCADOR 7).

Proibir de ir na escola, como castigo (SOCIOEDUCADOR 6).

Um profissional do meio fechado informou que o adolescente seria encaminhado para cumprimento de medida em meio aberto, com o seguinte relato: Finalizou o período de internação e estamos encaminhando o adolescente tal, porém, não se preocupe não se tem mais o que se fazer, não adianta gastar vela com defunto ruim. (sic) (SOCIOEDUCADOR 14). 
Já ouvi socioeducadores falar que as escolas não deveriam dar vagas para adolescentes em cumprimento de medidas socioeducativas, se referindo a eles como bandidos. -Socioeducador verbaliza para a mãe que ela é culpada da situação do filho. - Grita e coloca o dedo no nariz do adolescente. - Se recusa de levar família de adolescente para visitá-lo na Fundação Casa (SOCIOEDUCADOR 15).

Ocorreu que um socioeducador ao atender uma adolescente transexual, a profissional não reconheceu a identidade de gênero da adolescente e enfatizou que a chamaria pelo nome que constava na certidão de nascimento. Portanto, foi uma atitude preconceituosa, antiética e violadora (SOCIOEDUCADOR 18).

Fonte: Elaboração dos autores

De acordo com Costa (2006, p. 22) existem fundamentos éticos para a atuação de um socioeducador:

No que tange aos fundamentos éticos de sua atuação, o socioeducador deverá ser capaz de: • Conhecer, aceitar e praticar os princípios de uma deontologia da ação socioeducativa (Código de Ética Profissional) que tenha por base os direitos humanos. - Perceber e incorporar os direitos humanos como cosmovisão (visão do homem e do mundo) e não, somente, como dispositivo de natureza jurídica. • Discernir, claramente, as situações em que o uso da coerção física é inevitável daquelas em que é possível recorrer a outras formas de resolução dos conflitos. • Reconhecer a violência simbólica (tratamento humilhante e degradante) como uma das principais causas da violência reativa por parte dos educandos, principalmente em se tratando de medidas privativas e restritivas de liberdade. - Conhecer e saber aplicar, em sua atuação cotidiana, as Regras Mínimas das Nações Unidas para Funcionários Encarregados de Fazer Cumprir a Lei (COSTA, 2006, p. 22).

As falas dos sujeitos revelam que têm ocorrido práticas violadoras de direitos na execução das medidas socioeducativas de meio aberto. Observa-se que um total de $75 \%$ dos entrevistados presenciou algum tipo de violação em sua prática. Ao relacionar os dados com os fundamentos éticos da atuação do socioeducador e também com as características do que são direitos humanos, nota-se que essas condutas não se relacionam com direitos humanos, são práticas que ferem os fundamentos éticos que regem a atuação profissional, violando direitos e reforçando a violência.

$\mathrm{Na}$ questão anterior é feita uma reflexão sobre a importância de conhecer as normativas de sua profissão e de que a maioria dos entrevistados conhecem essas normativas, mas o que se verifica na prática, é que não se tem seguido um conjunto de normativas que possuem valores éticos.

Nos dias atuais, onde a realidade nos aponta para constantes contradições entre a lei e a realidade, constantes violações se apresentam. Precárias condições de trabalho, tanto para os profissionais inseridos neste contexto (contratos e salários), quanto para os sujeitos que cumprem medida socioeducativa; relatos de torturas, péssimas condições de estrutura das unidades, bem como a morte de adolescentes dentro do sistema, expressam uma realidade difícil. Cabe dizer também que as violações não estão apenas vinculadas a restrição e privação de liberdade. No meio aberto terão outras, mas terão, como por exemplo, quando a escola não quer aceitar os adolescentes que cumprem medida, ou aceita, mas de forma estigmatizada. Bem como, quando o cumprimento da prestação de serviço à comunidade reflete práticas punitivas e insalubres (SCHMIDT, 2017, p. 21).

É evidente, que deva haver um desequilíbrio entre teoria e prática, que ambas devem andar juntas, contudo, não tem ocorrido desta maneira. Sabemos que é possível ocorrer práticas violadoras de direitos, porém cabe olhar para a intensidade com que estas vêm ocorrendo e quais as motivações para assim, criarem-se mecanismos que visem a inibir ao máximo essas práticas.

Dessa forma, indagou-se ainda aos participantes da pesquisa se constar nas leis como deve atuar um socioeducador é suficiente para inibir essas práticas e facilitar a promoção efetiva dos direitos humanos e da ética. O Quadro 2 explicita os posicionamentos dos participantes da pesquisa acerca desse ponto. 
Quadro 2. Constar nas leis como deve atuar um socioeducador é suficiente?

Não, por que o educador/socioeducador precisa estar disponível para uma construção do indivíduo na subjetividade. Quando isso não acontece pode-se ficar numa atuação somente pelo cumprimento da lei (SOCIOEDUCADOR 3).

Não é o suficiente, é um norteador. O profissional precisa investir na sua formação com foco na área social (SOCIOEDUCADOR 4).

A lei tem a intenção de organizar e padronizar a atuação nacional da MSE e não é suficiente. Ela é uma referência que deve ser supervisionada, monitorada e fiscalizada (SOCIOEDUCADOR 5).

Não. É preciso investimento e qualificação profissional (SOCIOEDUCADOR 7).

Não. O trabalho com outros seres humanos exige supervisão e capacitação. Ambas tem a função de ajudar o profissional a compreender o sujeito em sua singularidade, sem atrapalhar o processo socioeducativo por questões pessoais (SOCIOEDUCADOR 8).

Não é suficiente. Necessita ter perfil e mesmo assim precisa de capacitação e supervisão continuada, necessita participar de espaços de discussões e trocas de experiências (SOCIOEDUCADOR 15).

Não, pois em nossa atuação há valores e princípios que antecedem as Leis. Tomar conhecimento das leis facilita e reforça uma ação mais eficaz voltada para o objetivo do trabalho, porém torna-se insuficiente se tivermos como única base de sustento para nossa atuação. Devemos buscar continuamente evoluir em nossa prática profissional, isso requer conhecimento para além do que está escrito em Leis (SOCIOEDUCADOR 19).

Fonte: Elaboração dos autores.

Ressalta-se que todos os participantes entenderam que é preciso constar nas leis como deve ser a atuação do socioeducador, porém esses acreditam que isso não é suficiente. A partir da leitura desses relatos, explicita-se que a teoria necessita da prática, ou seja, não adianta apenas constar em leis, se não houver envolvimento e interesse de todos os atores desse sistema para que haja uma atuação qualificada e humanizada que possa transformar e superar desafios. Faz-se necessário a consolidação da política de gestão de pessoas, pautadas na ética e nos direitos humanos.

De acordo com Almeida (2017, p. 1-2) a formação dos socioeducadores depende da participação e interesse de todos. O Plano Nacional do SINASE propõe que a gestão de pessoal, deve atender à necessidade coletiva e seu desafio é garantir além da seleção de pessoal a "constante atualização de equipe interdisciplinar; a definição do perfil profissional; e a especificação das atribuições de toda a equipe de atendimento até chegar à capacitação introdutória; à formação continuada; à formação em serviço; e à supervisão externa" (ALMEIDA, 2017, p. 1-2).

As declarações dos entrevistados revelam que constar nas leis como deve atuar um socioeducador não é o suficiente, as leis são norteadoras de uma prática, uma referência que deve ser supervisionada, monitorada e fiscalizada. Além disso, estes necessitam de investimento e capacitação continuada, assim como ter perfil profissional, espaços de discussões e trocas de experiências, como também conhecimento para além do que está nas leis.

Investigou-se ainda, se a ética impede que estes produzam práticas violadoras de direitos. A Figura 4 estampa esses resultados.

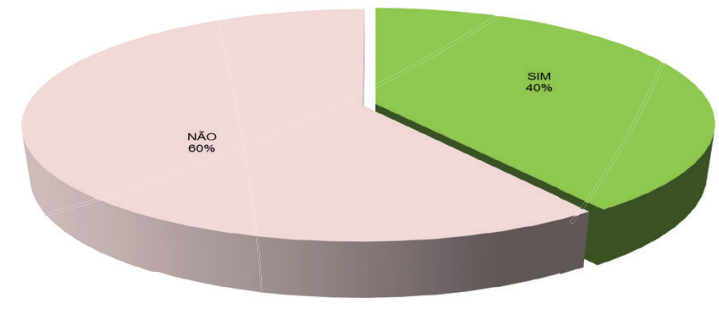

Figura 4. A ética impede que os socioeducadores produzam práticas violadoras de direitos?

Fonte: Elaboração dos autores.

A título de exposição dos argumentos apresentados pelos socioeducadores em defesa de suas posições presentes na Figura 4, é exposto o Quadro 3, na sequência. 
Quadro 3. Comparativo dos argumentos divergentes dos socioeducadores

\begin{tabular}{|c|c|}
\hline $\begin{array}{l}\text { Grupo } 1 \text { - A ética não im- } \\
\text { pede que os socioeduca- } \\
\text { dores produzam práticas } \\
\text { violadoras de direitos }\end{array}$ & $\begin{array}{l}\text { Grupo } 2 \text { - A ética impede } \\
\text { que os socioeducadores } \\
\text { produzam práticas } \\
\text { violadoras de direitos }\end{array}$ \\
\hline $\begin{array}{l}\text { Não, porque a ética tam- } \\
\text { bém se constitui com sua } \\
\text { trajetória de vida e de ex- } \\
\text { periências profissionais, } \\
\text { e infelizmente alguns } \\
\text { socioeducadores, por } \\
\text { inúmeros motivos, es- } \\
\text { quecem de quem são e } \\
\text { apenas reproduzem dis- } \\
\text { cursos e ações do senso } \\
\text { comum (SOCIOEDUCA- } \\
\text { DOR 3). }\end{array}$ & $\begin{array}{l}\text { Na minha opinião, a ética } \\
\text { impede que socioeduca- } \\
\text { dores produzam práticas } \\
\text { violadoras de direitos, } \\
\text { quando depende única e } \\
\text { exclusivamente do pro- } \\
\text { fissional. Mas viola-se di- } \\
\text { reitos quando há falta de } \\
\text { ética dos gestores, quan- } \\
\text { do não se tem os recur- } \\
\text { sos disponibilizados para } \\
\text { se efetivar o trabalho so- } \\
\text { cioeducativo (SOCIOE- } \\
\text { DUCADOR 16). }\end{array}$ \\
\hline
\end{tabular}

Não impede. É necessária uma reflexão sobre a prática, sustentada na teoria e não no senso comum. Só se consegue com supervisão e formação permanente (SOCIOEDUCADOR 6).

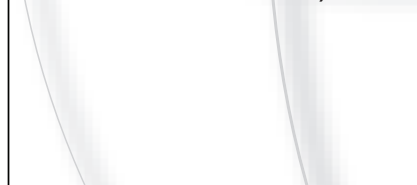

Não, acredito que a ética deve ser interiorizada de berço. Toda a profissão tem seu código de ética, se não as respeitá-las será punido e talvez possa perder o seu registro. Sendo assim, os profissionais primam o registro e não a ética (SOCIOEDUCADOR 17).

Fonte: Elaboração dos autores.

Os argumentos divergentes dos entrevistados contemplam suas percepções acerca de como vislumbram a ética no exercício de suas atribuições e de como esta pode contribuir ou não para evitar a violação de direitos. Os posicionamentos de NÃO e SIM, demonstram que a ética é um desafio, orientado por valores morais que regem o comportamento humano, cercado de complexidade na vida cotidiana, e que tem uma natureza individual, necessitando de vigilância constante para evitar as transgressões, pois todos se encontram vulneráveis.

Entretanto, ao longo das discussões anteriores e a partir dos dados apresentados no último gráfico, observa-se que $60 \%$ acreditam que ela não impede e observa-se também que $75 \%$ dos socioeducadores já presenciaram situações de violações de direitos, ou seja, práticas não éticas. Portanto, os dados se relacionam e confirmam que a ética não tem impedido as violações de direitos como poderia, isto é, impede, porém, em menor escala, não sendo suficiente se considerarmos que ela é a natureza da prática educativa.

É perceptível nas falas dos entrevistados que pode existir uma série de fatores complexos que influenciam na tomada de decisão quanto a ser ético ou não, existem contingências que podem ir além do sujeito e para que a conduta ética possa acontecer ela dependerá também de um amparo ou atenção institucional, que muitas vezes pode não ocorrer.

Partindo desse pressuposto, acredita-se que na socioeducação pode-se observar variadas situações em que o profissional poderá realizar a tomada de decisão, como por exemplo, ele poderá realizar um enfrentamento e não permitir nenhuma situação de violação de direitos, assumindo as consequências, poderá não se preocupar em ter uma postura ética e mesmo tendo uma postura ética em situações anteriores este poderá deixar de ter diante da situação na qual está exposto. Assim a tomada de decisão será sempre realizada a partir de um contexto de complexidade.

Freire (1996) menciona, que não é possível ao sujeito ético viver sem estar permanentemente exposto à transgressão da ética. Assim, acredita-se que o que pode mudar são as atitudes que serão tomadas diante das situações, se irão denunciar e enfrentar as consequências, se irão se calar por medo, se terão atitudes respeitosas ou se serão preconceituosas e violadoras de direitos, porque o sujeito ético sempre estará exposto a situações que demandam uma ação e o silenciamento também pode ser visto como uma ação.

Como a ética é a natureza da prática educativa, 
acredita-se que não se pode aceitar sua transgressão e que é necessário lutar para impedir que continue acontecendo seja por qualquer razão. Deve ser inadmissível transgredi-la e não natural, pois, em qualquer hipótese, quando isso acontece todos os envolvidos no sistema perdem, sejam eles profissionais, população, entre outros.

Seguidamente, perguntou-se aos sujeitos quais opções podem contribuir para que socioeducadores produzam práticas violadoras de direitos. Os resultados estão expressos na Figura 5. Assinala-se que os participantes poderiam escolher mais de uma opção.

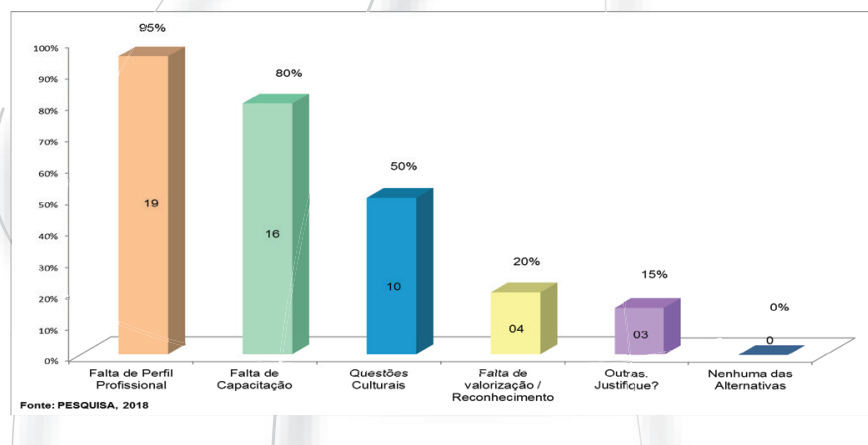

Figura 5. Quais opções podem contribuir para práticas violadoras de direitos?

Fonte: Elaboração dos autores.

Considerando a amostra de 20 entrevistados, nota-se que dentre as opções, a falta de perfil profissional foi escolhida em $1^{\circ}$ lugar por 19 (95\%), seguida da falta de capacitação escolhida por 16 (80\%), questões culturais foi escolhida por 10 (50\%), falta de valorização/ reconhecimento por $4(20 \%)$ e outras questões, foram escolhidas por 3 (15\%), cujas justificativas são expostas a seguir:

Falta de supervisão, sofrer ameaças, ter medo. Exemplo: Poucos socioeducadores denunciam o tráfico nos bairros. Negligência também é uma violação (SOCIOEDUCADOR 8).

Falta de recursos materiais, humanos e econômicos (SOCIOEDUCADOR 15).

Falta de entendimento por parte dos gestores, comprometendo o trabalho (SOCIOEDUCADOR 16).

A partir dos dados apresentados e das falas dos sujeitos, evidencia-se que existem muitos fatores que podem contribuir para que socioeducadores produzam práticas violadoras de direitos.

Primeiramente é importante nos reconhecermos como parte deste processo e sairmos do imediatismo que muitas vezes move o trabalho institucional. Cabe então pensarmos propostas coletivas (equipes técnicas, demais servidores, familiares, legisladores e administradores, conseIhos de direitos) de superação destas questões. Estas podem ser no âmbito do diálogo com dirigentes e superiores, mas também no âmbito da denúncia fundamentada através de instrumentos legais. Para isso é importante o conhecimento da realidade, da instituição, e da legislação, em um posicionamento baseado nos princípios éticos de direitos humanos (SCHMIDT, 2017, p. 21).

A primeira questão que se perguntou aos sujeitos na pesquisa refere-se justamente ao perfil profissional. A partir dos dados obtidos, refletiu-se que o perfil profissional se torna um requisito fundamental na contratação de um socioeducador, mas que na prática não é dada a devida importância.

Os dados novamente permitem uma relação: na Figura 1, a falta de perfil profissional aparece como sendo um dos motivos que mais contribui para que os entrevistados produzam práticas violadoras de direitos, seguido de outros também importantes. Alguns problemas podem ser solucionados inicialmente antes da violação de direitos acontecerem, outros, durante e outros depois, o que exige uma prática cada vez mais transformadora e reflexiva.

Conforme aponta Schmidt (2017), é importante que todos se reconheçam como parte do processo e que se pense em propostas coletivas de superação. Acredita-se que quando depende apenas do sujeito, esse deve refletir sua prática e, mesmo assim, pode depender do auxílio dos demais envolvidos, até mesmo se precisar ser denunciado.

Sequencialmente, perguntou-se aos sujeitos se para esses, os socioeducadores se preocupam em ter uma atuação ética? Assim, considerando uma escala de 1 a 5 em que o "1" pode expressar o discordo completamente e o " 5 " pode evidenciar o concordo plenamente. Os resultados estão estampados na Figura 6. 


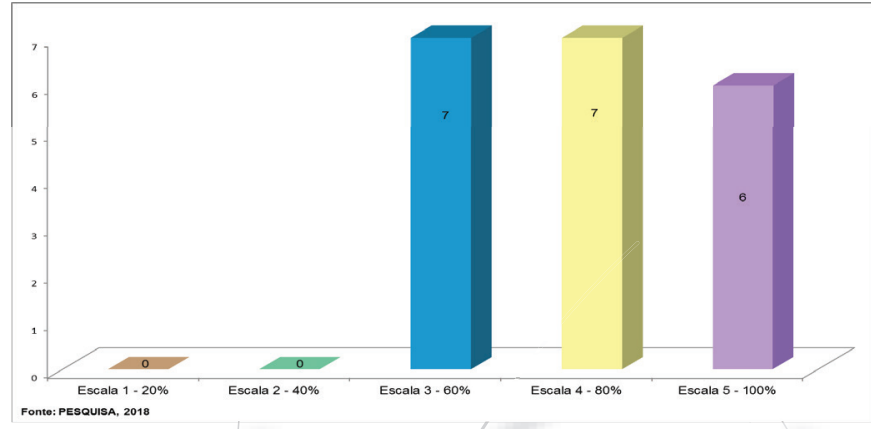

Figura 6. Os socioeducadores se preocupam em ter uma atuação ética?

Fonte: Elaboração dos autores.

Observa-se que dos 20 sujeitos da amostra, 6 acreditam que $100 \%$ dos socioeducadores se preocupam em ter uma atuação ética, 7 acreditam que $80 \%$ se preocupam e 7 acreditam que $60 \%$ se preocupam. Portanto, os dados indicam que mais de $60 \%$ dos sujeitos pesquisados acreditam que os profissionais se preocupam em ter uma atuação ética.

A perspectiva da ética é um importante instrumento para responder a estas questões. Pois não basta estudarmos e aprender sobre os direitos, precisamos internalizá-los e compreendê-los como instrumentos de ação na defesa de nosso trabalho com estes adolescentes. É fazermos uma opção por um projeto de sociedade emancipatório, na direção da construção de uma nova sociedade, que propicie a busca e a vivência de novos valores, o que, evidentemente supõe a erradicação de todos os processos de exploração e opressão (SCHMIDT, 2017, p. 20).

A preocupação em ter uma atuação ética é de fato muito importante, porém somente se preocupar não muda a realidade e a distância entre a teoria e a prática quando há muitos relatos sobre violações de direitos, é preciso internalizar e praticar os princípios éticos da socioeducação diariamente, só assim a ética de fato poderá garantir a observância dos direitos humanos.

Para finalizar, perguntou-se aos sujeitos se é necessário que socioeducadores exerçam uma reflexão ética sobre sua atuação. Consideraram uma escala de 1 a 5 em que o "1" pode expressar o discordo completamente e o " 5 " pode evidenciar o concordo plenamente. Confira na Figura 7 os resultados.

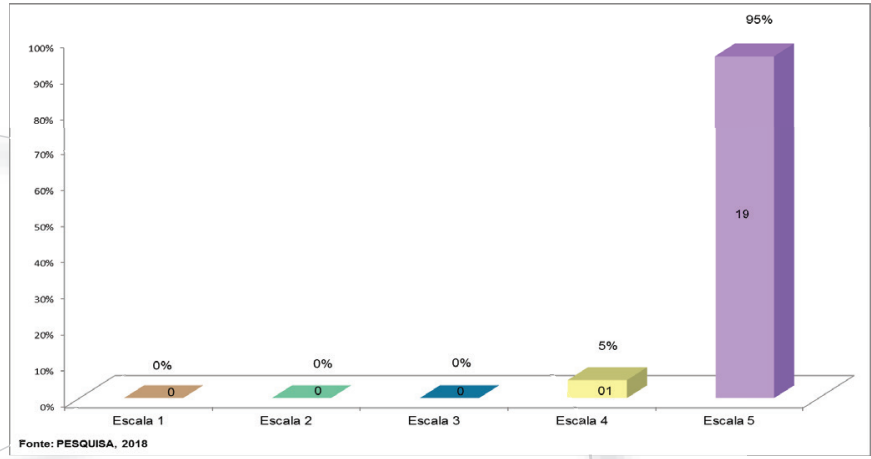

Figura 7. Os socioeducadores precisam fazer reflexão ética sobre suas atuações?

Fonte: Elaboração dos autores.

Observa-se que dos 20 profissionais, 19 (95\%) acreditam plenamente ser necessário que se exerça uma reflexão ética e $1(5 \%)$ acredita ser necessário, portanto todos os entrevistados acreditam na necessidade de se repensar e refletir sobre a sua atuação constantemente.

É pensando criticamente a prática de hoje ou de ontem que se pode melhorar a próxima prática. $\mathrm{O}$ próprio discurso teórico, necessário à reflexão crítica, tem de ser de tal modo concreto que quase se confunda com a prática. O seu "distanciamento" epistemológico da prática enquanto objeto de sua análise, deve dela "aproximá-lo" ao máximo. Quanto melhor faça esta operação tanto mais inteligência ganha da prática em análise e maior comunicabilidade exerce em torno da superação da ingenuidade pela rigorosidade. Por outro lado, quanto mais me assumo como estou sendo e percebo a ou as razões de ser de porque estou sendo assim, mais me torno capaz de mudar, de promover-me, no caso, do estado de curiosidade ingênua para o de curiosidade epistemológica. Não é possível a assunção que o sujeito faz de si numa certa forma de estar sendo sem a disponibilidade para mudar. Para mudar e de cujo processo se faz necessariamente sujeito também (FREIRE, 1996, p. 18).

Acredita-se que esse processo deve ser constante e que cada profissional deverá estar disposto a mudar. Observaram-se, nas falas dos entrevistados, violações de direitos, assim como, sobre a ética não estar 
cumprindo sua missão como poderia. Sem essa reflexão ética corre-se o risco de se basear toda uma prática em atitudes preconceituosas e moralistas. A reflexão ética sobre a prática ocasiona a possibilidade de repensar, refazer, recomeçar, permitindo que as garantias fundamentais de proteção e de direitos humanos sejam à base das práticas dos socioeducadores.

\section{Considerações Finais}

Buscou-se nesse estudo analisar se a ética aliada aos direitos humanos inibe práticas violadoras de direitos na socioeducação. Supõe-se que uma prática socioeducativa sem embasamento ético e não voltada aos direitos humanos corre o risco de ser norteada de forma desumana e violadora de direitos. Acredita-se que o objetivo dessa pesquisa foi atingido com descobertas interessantes para a compreensão do fenômeno estudado.

Portanto, aferiu-se que o perfil profissional é um requisito indispensável na contratação de um socioeducador e que o conhecimento sobre o que são direitos humanos é fundamental, sendo a ética uma grande aliada no combate às violações de direitos com concordância entre os sujeitos de que os princípios do SINASE e do ECA possuem valores éticos e que os entrevistados possuem conhecimento dessas leis.

Verificou-se que a maioria dos sujeitos pesquisados já presenciou alguma situação de violação de direitos, desse modo, os socioeducadores acreditam que apenas constar nas leis como deve ser sua atuação não é o suficiente. De acordo com a maioria dos sujeitos, a ética não inibe práticas violadoras de direitos como poderia. Entre os fatores que pode contribuir para práticas violadoras de direitos, observou-se que a falta de perfil profissional é a que mais contribui para isso, seguida de outras também importantes. Para os pesquisados, a maior parte dos profissionais se preocupam em ter uma atuação ética, como também acreditam que é necessário que exerçam uma reflexão ética sobre sua prática.
A partir das análises, observações significativas vieram à tona e inclusive refutaram a hipótese inicial, qual seja a de que a ética aliada aos direitos humanos inibe práticas violadoras de direitos. Saber que a maioria dos sujeitos presenciou socioeducadores violando direitos humanos corrobora o fato de que a ética, por si só, não inibe práticas violadoras como poderia, contudo, defendemos que os princípios éticos na prática profissional quando exercido de fato, contribui para propiciar a efetivação dos direitos e o reconhecimento da igual dignidade do ser humano dentro do processo de reabilitação ao convívio social, de crianças e adolescentes atendidas.

Para tanto, ela depende de um conjunto de fatores, que podem ser de interesse do sujeito, do coletivo e/ou do meio social e que as propostas apresentadas possam ser efetivadas. Portanto, é possível a partir das análises, elencar algumas propostas que, se efetivadas, podem inibir práticas violadoras de direitos e transformar o cenário atual. Nessa perspectiva, compreende-se que é indispensável que os socioeducadores possuam um perfil profissional voltado para área de trabalho e que este fator seja considerado em sua contratação, como também tenham conhecimento aprofundado sobre Direitos Humanos e sobre as normativas que regulam sua prática, como o ECA e o SINASE e outras. Além disso, os profissionais, gestores e outros envolvidos no sistema, precisam nortear suas práticas cotidianas, na ética para inibir as violações de direitos humanos, como também precisam além de conhecer essas leis e normativas que estas sejam internalizadas e praticadas e que todos os atores do sistema socioeducativo se reconheçam como parte essencial na luta pela efetivação das políticas públicas.

Alicerçados nessas propostas, acredita-se que a ética aliada aos direitos humanos tem potencial de transformação na luta pelo combate às violações de direitos, podendo inibir ao máximo a sua ocorrência, o que representa um processo de construção em busca de sua efetivação. 


\section{REFERÊNCIAS}

ALMEIDA, Riezo Silva. Formação e Qualificação dos Atores do SINASE. Especialização em Políticas Públicas e Socioeducação, Brasília, 2017. Disponível em: <http://ens.sinase.sdh.gov.br/ens2/index. php?searchword=riezo $\% 20$ s $\% 20$ almeida\&ordering $=$ ne west \&searchphrase=all\&limit=20\&Itemid=181\&option $=c$ om_search>. Acesso em: 09 jul. 2018.

BRASIL. As bases éticas da ação socioeducativa: referenciais normativos e princípios norteadores. Coord. Antônio Carlos Gomes da Costa. Brasília: Secretaria Especial dos Direitos Humanos, 2006. Disponível em: <http://ens.sinase.sdh.gov.br/ens2/ images/Biblioteca/Livros_e_Artigos/material_curso_de formacao_da_ens/As $\% 20$ Bases $\% 20$ Eticas $\% 20$ da $\% 20$ A\%C3\%A7\%C3\%A30\%20Socioeducativa.pdf>. Acesso em: 17 jul. 2018.

BRASIL. Parâmetros para a formação do socioeducador: uma proposta inicial para reflexão e debate. Coord. Antônio Carlos Gomes da Costa. Brasília: Secretaria Especial dos Direitos Humanos, 2006. Disponível em: <http://ens.sinase.sdh.gov.br/ens2/images/ Biblioteca/Livros_e_Artigos/material_curso_de_formacao_da_ens/Par\%C3\%A2metros $\% 20$ para $\% 20$ a $\% 20$ Forma\%C3\%A7\%C3\%A30\%20do\%20Socioeducador. pdf>. Acesso em: 17 jul. 2018.

BRASIL. Secretaria Especial dos Direitos Humanos. Sistema Nacional de Atendimento Socioeducativo. CONANDA, Brasília - DF, 2006. Disponível em: <http:// www.conselhodacrianca.al.gov.br/sala-de-imprensa/publicacoes/sinase.pdf>. Acesso em: 17 jul. 2018.

FABRIZ, Daury César. Bioética e direitos fundamentais. 1. ed. Belo Horizonte, Editora Mandamentos, 2003. FREIRE, Paulo. Pedagogia da autonomia: saberes necessários à prática educativa. São Paulo: Paz e Terra, 1996.

BRASIL. Estatuto da Criança e do adolescente. Lei n8.069, de 13 de julho de 1990. Brasília, DF, 1990. Disponível em: <http://www.planalto.gov.br/ccivil_03/leis/ I8069.htm>. Acesso em: 17 jul. 2018.
MORAIS, Aline Cristina de; MALFITANO, Ana Paula Serrata. Medidas socioeducativas em São Paulo: os serviços e os técnicos. Psicologia \& Sociedade, v. 26, n. 3, p. 613621, 2014. Disponível em: <http://www.scielo.br/scielo. php?pid=S0102-71822014000300010\&script $=$ sci_ abstract\&tlng=pt>. Acesso em: 20 jun. 2018.

ONU. Declaração Universal dos Direitos Humanos: Resolução 217, Assembleia Geral das Nações Unidas (1948). UNIC Rio, Rio de Janeiro, 2009. Disponível em: <http://www.onu.org.br/img/2014/09/DUDH.pdf> Acesso em: 09 jul. 2018.

SCHMIDT, Fabiana. Ética, Direitos Humanos e Princípios jurídicos Nacionais e Tratados Internacionais sobre Direitos de Crianças e Adolescentes. Especialização em Políticas Públicas e Socioeducação, Brasília, 2017. Disponível em: <http://ens.sinase.sdh.gov.br/ens2/index. php? searchword=fabiana $\% 20$ schmidt\&searchphrase=al I\&Itemid=181\&option=com_search>. Acesso em: 09 jul. 2018.

PAES, Paulo Cesar Duarte; ADIMARI, Maria Fernandes. (Orgs.). Socioeducação e intersetorialidade: formação continuada de socioeducadores. Campo Grande-MS: Ed. UFMS, 2015. Disponível em: <http://ens. sinase.sdh.gov.br/ens2/images/Biblioteca/Livros_e_Artigos/ufms/UFMS.\%202015.\%20Caderno\%206.\%20 Livro\%20intersetorialidade\%20-\%20completo.pdf>. Acesso em: 22 jul. 2018. 